\title{
Simultaneous Determination of Caffeine and Water-Soluble Vitamins in Energy Drinks by HPLC with Photodiode Array and Fluorescence Detection
}

\author{
Anna Gliszczyńska-Świgło • Iga Rybicka
}

Received: 11 March 2014 / Accepted: 15 April 2014 /Published online: 8 May 2014

(C) The Author(s) 2014. This article is published with open access at Springerlink.com

\begin{abstract}
The high-performance liquid chromatography (HPLC) method with photodiode array (PDA) and fluorescence (FL) detection for the simultaneous separation and determination of caffeine and water-soluble vitamins is described. The method is relatively rapid: 13 compounds can be analyzed within 30 min: caffeine; ascorbic acid (vitamin C); thiamine (vitamin $\mathrm{B}_{1}$ ); riboflavin 5-phosphate (FMN, flavin mononucleotide) and riboflavin (vitamin $\mathrm{B}_{2}$ ); nicotinic acid and nicotinamide (vitamin $\mathrm{B}_{3}$ ); pantothenic acid (vitamin $\mathrm{B}_{5}$ ); pyridoxal, pyridoxamine, and pyridoxine (vitamin $\mathrm{B}_{6}$ ); folic acid (vitamin $\mathrm{B}_{9}$ ); and cyanocobalamin (vitamin $\mathrm{B}_{12}$ ). This HPLC method is designated for quantification of caffeine and water-soluble vitamins in liquid and tablet energy drinks as well as for determination of vitamins in vitamin supplements. The method was validated in terms of linearity, limit of detection (LOD) and quantification (LOQ), accuracy, and instrument precision. The LODs determined using HPLCPDA ranged from 13 to $121 \mathrm{ng} \mathrm{mL}^{-1}$ and using HPLC-FL were between 8 and $61 \mathrm{ng} \mathrm{mL}^{-1}$. Intra- and interday instrument precisions for liquid energy drink, expressed as relative standard deviation (RSD), were less than 1.87 and $1.73 \%$, respectively, and less than 1.44 and $1.83 \%$, respectively, for tablet energy drink. The method could be useful in the quantitative analysis of caffeine and of water-soluble vitamins in energy drinks and vitamin supplements.
\end{abstract}

Keywords Water-soluble vitamin · Vitamin B · Caffeine . HPLC $\cdot$ Energy drink $\cdot$ Vitamin supplement

\footnotetext{
A. Gliszczyńska-Świgło $(\bowtie) \cdot$ I. Rybicka

Faculty of Commodity Science, Poznań University of Economics, al. Niepodległości 10, 61-875 Poznań, Poland

e-mail: a.gliszczynska-swiglo@ue.poznan.pl
}

\section{Introduction}

Energy drinks are one of the fastest growing soft drink markets around the world (Euromonitor 2013). They have been recently consumed in different societies, especially by younger consumers, because they give power throughout the day due to caffeine, vitamins, well-absorbed monosaccharides, and other ingredients such as taurine (Euromonitor 2013; Sather and Vernig 2011). The results of a European survey of 52,000 respondents from 16 countries showed that approximately $30 \%$ of adults are regularly drinking caffeineenriched beverages (Higdon and Frei 2006). Vitamins and dietary supplements are also a relevant category in the field of consumer's health. In 2013, their worldwide value was estimated at US\$84.4 billion (Euromonitor 2014).

Caffeine is a xanthine alkaloid acting as a central nervous system stimulant. It temporarily increases blood pressure and eliminates drowsiness. Caffeine is classified by the Food and Drug Administration as generally recognized as safe (GRAS), and its common consumption, below $400 \mathrm{mg}$ per day (Zucconi et al. 2013), has low health risk or even its protective effects against some diseases, including Parkinson disease (Prediger 2010), and certain types of cancer have been reported (Uccella et al. 2013; Miura et al. 2014). However, the overconsumption of this drug could potentially be harmful (Jiang et al. 2013).

Water-soluble vitamins include nine water-soluble groups of compounds (eight B vitamins and vitamin C) showing diverse biochemical functions. Each "vitamin" refers to a number of vitamin derivatives that all show the biological activity associated with a particular vitamin. Although the Recommended Dietary Allowances (RDAs) for vitamins are relatively small, even the mild deficiency of one of them can lead to serious health problems. Nutritional deficit of vitamin $\mathrm{B}_{1}$ (thiamine) can lead to beriberi disease manifested by cardiovascular disorders and impairment of digestive and 
nervous systems (Sriram et al. 2012). Deficiencies of vitamin $\mathrm{B}_{2}$ (riboflavin and its co-enzymes: flavin mononucleotide (FMN) and flavin adenine dinucleotide (FAD)), vitamin $\mathrm{B}_{3}$ (niacin), vitamin $\mathrm{B}_{6}$ (pyridoxine, pyridoxamine, pyridoxal), and vitamin $\mathrm{B}_{7}$ (biotin) mainly occur as skin inflammation and discomfort from the gastrointestinal tract (Powers 2003; Ball 2006). Since vitamin $B_{5}$ (pantothenic acid) is found in most food products, its deficiency is relatively rare (Ball 2006).

Several methods exist for the determination of caffeine as a single component or in combination with other drugs in pharmaceutical formulations or biological matrix of food (Patil 2012). The most popular include chromatographic techniques such as high-performance liquid chromatography (HPLC), high-performance thin layer chromatography (HPTLC), or capillary electrophoresis with ultraviolet (UV) or mass spectrometry (MS) detection. They allow the determination of caffeine as a single compound in herbal products and energy drinks or its separation from other alkaloids in chocolate, tea, coffee, urine, or serum (Abourashed and Mossa 2004; Tokusoglu and Kemal 2002; Jafari et al. 2011; Perrone et al. 2008; Peri-Okonny et al. 2005; Zhao and Lunte 1997). Caffeine can be separated from polyphenols in tea and coffee (Hadad et al. 2012; Samanidou et al. 2012; Poerner and Bragagnolo 2013) or from other drugs in pharmaceutical preparations (Gámiz-Gracia and Luque de Castro 1997; Zen and Ting 1997; Sultan et al. 2013).

For vitamin-enriched energy drinks, a micellar electrokinetic chromatography method was proposed to determine 2 aminoethanesulfonic acid, nicotinamide, pyridoxine, caffeine, riboflavin, and thiamine (Okamoto et al. 2002). Sather and Vernig (2011) and Leacock et al. (2011) described the HPLC method for the determination of caffeine and vitamin $B_{6}$ (pyridoxine). The HPTLC for determination of riboflavin, pyridoxine, nicotinamide, caffeine, and taurine in energy drinks was developed by Aranda and Morlock (2006), but HPTLC is a less commonly used technique than HPLC.

In the present study, a new HPLC method with photodiode array (PDA) detection was proposed for determination of caffeine and water-soluble vitamins. The method with fluorescence (FL) detection for determination of vitamins $B_{2}$ (in the form of FMN and riboflavin) and $\mathrm{B}_{6}$ (as pyridoxal, pyridoxamine, and pyridoxine) was also described. According to the authors' knowledge, there is no chromatographic method that allows separation and determination of caffeine in combination with most of the water-soluble vitamins. Moreover, simultaneous PDA and FL detection of these compounds cannot be found in the literature. The proposed HPLC-PDA-FL method is dedicated for the determination of caffeine and water-soluble vitamins in energy drinks. The method can be also an alternative for existing methods of water-soluble vitamin determinations in pharmaceutical preparations.

\section{Materials and Methods}

Materials

Thiamine hydrochloride (vitamin $\mathrm{B}_{1}$ ) and pyridoxine hydrochloride (vitamin $\mathrm{B}_{6}$ ) were purchased from Fluka (Buchs, Switzerland). Pyridoxamine dihydrochloride, pyridoxal hydrochloride (vitamin $\mathrm{B}_{6}$ ), cyanocobalamin (vitamin $\mathrm{B}_{12}$ ), riboflavin and riboflavin 5 '-monophosphate sodium salt hydrate (FMN, vitamin $\mathrm{B}_{2}$ ), nicotinic acid and nicotinamide (vitamin $\mathrm{B}_{3}$ ), folic acid (vitamin $\mathrm{B}_{9}$ ), pantothenic acid sodium salt (vitamin $\mathrm{B}_{5}$ ), and caffeine were purchased from Sigma (St. Louis, MO, USA). Ascorbic acid (vitamin C) was from Merck (Darmstadt, Germany). Methanol of HPLC grade was from Chempur (Piekary Śląskie, Poland).

Certified reference materials (CRM; Cerilliant, TX, USA), caffeine solution (1 $\mathrm{mg} \mathrm{mL}^{-1}$ in methanol), pyridoxine hydrochloride (vitamin $\mathrm{B}_{6}$ ) solution (1 $\mathrm{mg} \mathrm{mL}^{-1}$ in methanol), and nicotinamide (vitamin $\mathrm{B}_{3}$ ) solution $\left(1 \mathrm{mg} \mathrm{mL}^{-1}\right.$ in methanol), were purchased from Sigma-Aldrich (Munich, Germany). CRMs of other vitamins were not commercially available or were withdrawn from the market.

Demineralized water was obtained from a Hydrolab System (Hydrolab, Wiślina, Poland) and filtered by Millipore system using $0.45 \mu \mathrm{m}$ nylon filters (Waters, Milford, MA, USA). Energy drinks and vitamin supplements were purchased in local supermarkets and pharmacies.

\section{Sample Preparation}

Liquid energy drinks were analyzed directly after ultrasonic degassing for $10 \mathrm{~min}$. Energy drinks and vitamin supplements in tablets were weighted, dissolved in $150 \mathrm{~mL}$ of demineralized water, and sonicated for $10 \mathrm{~min}$. Subsequently, the sample was transferred to a $200-\mathrm{mL}$ volumetric flask and filled up with water to the mark. Samples were protected from light by aluminum foil and analyzed using HPLC. Before the HPLC analysis, the samples were centrifuged for $5 \mathrm{~min}$ at 14,000 $\mathrm{g}$ (microcentrifuge Eppendorf MiniSpin plus, Warsaw, Poland). No supernatant for the tested products was observed; thus, the recovery studies were not necessary. For each type of product, three independent samples were prepared.

HPLC Determination of Caffeine and Water-Soluble Vitamins

A Waters 600 high-performance liquid chromatograph (Waters, Milford, MA, USA) equipped with Nova-Pak $\mathrm{C}_{18}$ column $(150 \mathrm{~mm} \times 3.9 \mathrm{~mm}, 5 \mu \mathrm{m})$ fitted with $\mu$ Bondapak $\mathrm{C}_{18}$ cartridge guard column (Waters, Milford, MA, USA) was used. A gradient of mobile phase consisting of methanol (solvent $\mathrm{A}$ ) and $0.05 \mathrm{M} \mathrm{NaH}_{2} \mathrm{PO}_{4}$ containing $0.005 \mathrm{M}$ hexanesulfonic acid, pH 3.0 (solvent $\mathrm{B}$ ) was developed and 
used according to the following program: linear increment starting with $10 \%$ A to $40 \%$ A for $20 \mathrm{~min}$ and the return to the initial conditions within the next $10 \mathrm{~min}$ with the flow rate of $1 \mathrm{~mL} \mathrm{~min}^{-1}$. The injection volume was $20 \mu \mathrm{L}$. The eluate was detected using a Waters 996 PDA detector set at the wavelength characteristic for appropriate vitamin or caffeine. Moreover, a Waters 474 scanning fluorescence detector set at an excitation wavelength of $290 \mathrm{~nm}$ and emission at $390 \mathrm{~nm}$ for vitamin $\mathrm{B}_{6}$ or $450 \mathrm{~nm}$ excitation and $530 \mathrm{~nm}$ emission wavelengths for vitamin $B_{2}$ was used. Emission slit width was $10 \mathrm{~nm}$, fluorometer gain was 10 , and attenuation was 1 . Caffeine and vitamins were identified by comparison of their retention times to those of corresponding standards. Additionally, UV or ultraviolet/visible (UV/VIS) absorption spectra measured using the PDA detector were used to confirm the identity and purity of the compounds.

\section{Method Validation}

Validation of the HPLC method included linearity, sensitivity, accuracy, and instrument precision. Quantification of caffeine and vitamins was performed using an external standard method. At least seven-point calibration curves $(n=3)$ were prepared with the aqueous solutions of standards at the levels covering those in the assessed samples.

Table 1 HPLC detection wavelengths and retention times of caffeine and water-soluble vitamins

\begin{tabular}{lll}
\hline Compound & Detection [nm] & $t_{\mathrm{R}} \pm \mathrm{SD}[\mathrm{min}]$ \\
\hline Ascorbic acid $^{\mathrm{a}}$ & 245 & $1.59 \pm 0.01$ \\
${\text { Nicotinic acid }\left(\mathrm{B}_{3}\right)^{\mathrm{b}}}_{\text {Nicotinamide }\left(\mathrm{B}_{3}\right)^{\mathrm{a}}}$ & 260 & $2.20 \pm 0.05$ \\
Pantothenic acid $\left(\mathrm{B}_{5}\right)^{\mathrm{a}}$ & 260 & $4.25 \pm 0.14$ \\
Pyridoxal $\left(\mathrm{B}_{6}\right)^{\mathrm{b}}$ & 202 & $7.94 \pm 0.10$ \\
& 290 & $9.85 \pm 0.07$ \\
${\text { Pyridoxamine }\left(\mathrm{B}_{6}\right)^{\mathrm{b}}}$ & 290 & $9.89 \pm 0.06$ \\
& ex. 290/em. 390/em. 390 & $11.23 \pm 0.07$ \\
Pyridoxine $\left(\mathrm{B}_{6}\right)^{\mathrm{a}}$ & 290 & $11.25 \pm 0.06$ \\
& ex. 290/em. 390 & $12.85 \pm 0.08$ \\
${\text { Thiamine }\left(\mathrm{B}_{1}\right)^{\mathrm{a}}}^{\text {FMN }\left(\mathrm{B}_{2}\right)^{\mathrm{a}}}$ & 245 & $12.86 \pm 0.08$ \\
& 450 & $15.69 \pm 0.20$ \\
Caffeine $^{\mathrm{a}}$ & ex. 450/em. 530 & $16.30 \pm 0.05$ \\
${\text { Folic acid }\left(\mathrm{B}_{9}\right)^{\mathrm{a}}}_{\text {Cyanocobalamin }\left(\mathrm{B}_{12}\right)^{\mathrm{b}}}$ & 270 & $16.33 \pm 0.05$ \\
Riboflavin $\left(\mathrm{B}_{2}\right)^{\mathrm{a}}$ & 280 & $18.58 \pm 0.04$ \\
& 450 & $19.45 \pm 0.03$ \\
& ex. 450/em. 530 & $20.90 \pm 0.05$ \\
& & $20.94 \pm 0.05$ \\
\hline
\end{tabular}

${ }^{\mathrm{a}}$ From six injections of a real sample performed within two consecutive days $(n=12)$

${ }^{\mathrm{b}}$ From standard injections

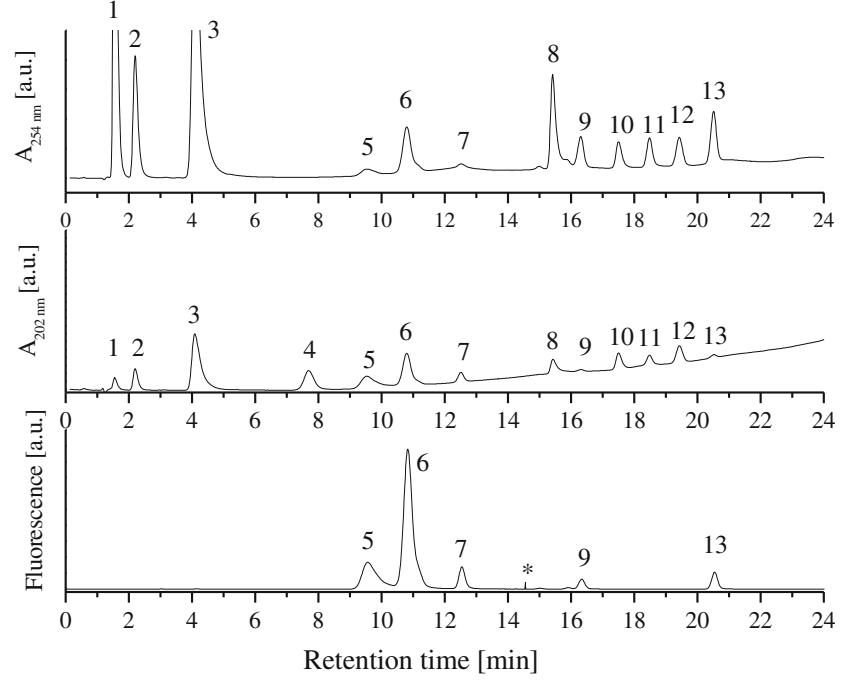

Fig. 1 The HPLC separation of caffeine and water-soluble vitamin standards monitored at 254 and $202 \mathrm{~nm}$ and using a fluorescence detector (290/390 $\mathrm{nm}$ for vitamin $\mathrm{B}_{6}$ and $450 / 530 \mathrm{~nm}$ for vitamin $\mathrm{B}_{2}$ ). Asterisk, the change of the excitation and emission wavelengths. 1, ascorbic acid (vitamin $\mathrm{C}$ ); 2, nicotinic acid (vitamin $\mathrm{B}_{3}$ ); 3, nicotinamide (vitamin $\mathrm{B}_{3}$ ); 4, pantothenic acid (vitamin $\mathrm{B}_{5}$ ); 5, pyridoxal (vitamin $\mathrm{B}_{6}$ ); 6 , pyridoxamine (vitamin $\mathrm{B}_{6}$ ); 7 , pyridoxine (vitamin $\mathrm{B}_{6}$ ); 8 , thiamine (vitamin $\mathrm{B}_{1}$ ); 9, riboflavin 5-phosphate (FMN, flavin mononucleotide; vitamin $\left.\mathrm{B}_{2}\right) ; 10$, caffeine; 11 , folic acid (vitamin $\left.\mathrm{B}_{9}\right) ; 12$, cyanocobalamin (vitamin $\mathrm{B}_{12}$ ); and 13 , riboflavin (vitamin $\mathrm{B}_{2}$ )

Accuracy of the method was verified using solutions of CRMs: nicotinamide (vitamin $\mathrm{B}_{3}$ ), pyridoxine (vitamin $\mathrm{B}_{6}$ ), and caffeine. From each CRM, five different solutions in demineralized water were prepared $(1,5,10,25$, and $50 \mu \mathrm{g} \mathrm{mL}^{-1}$ for nicotinamide and pyridoxine and 50, 100, 200,300 , and $500 \mu \mathrm{g} \mathrm{mL}^{-1}$ for caffeine), and their concentrations were determined using an appropriate calibration curve. Each concentration was prepared in triplicate. The

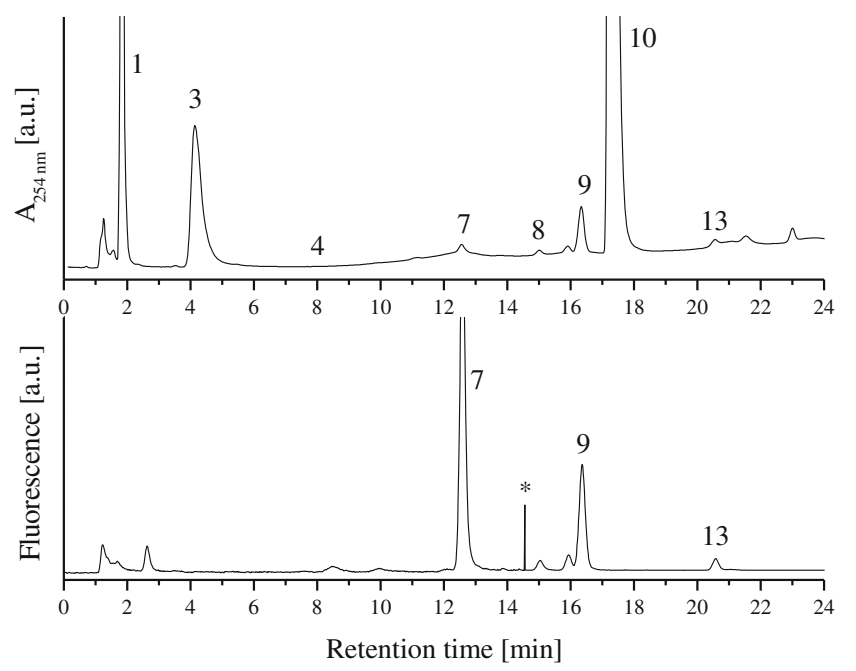

Fig. 2 HPLC chromatograms of energy drink monitored at $254 \mathrm{~nm}$ and using a fluorescence detector. Asterisk, the change of the excitation and emission wavelengths. Legend as in Fig. 1 

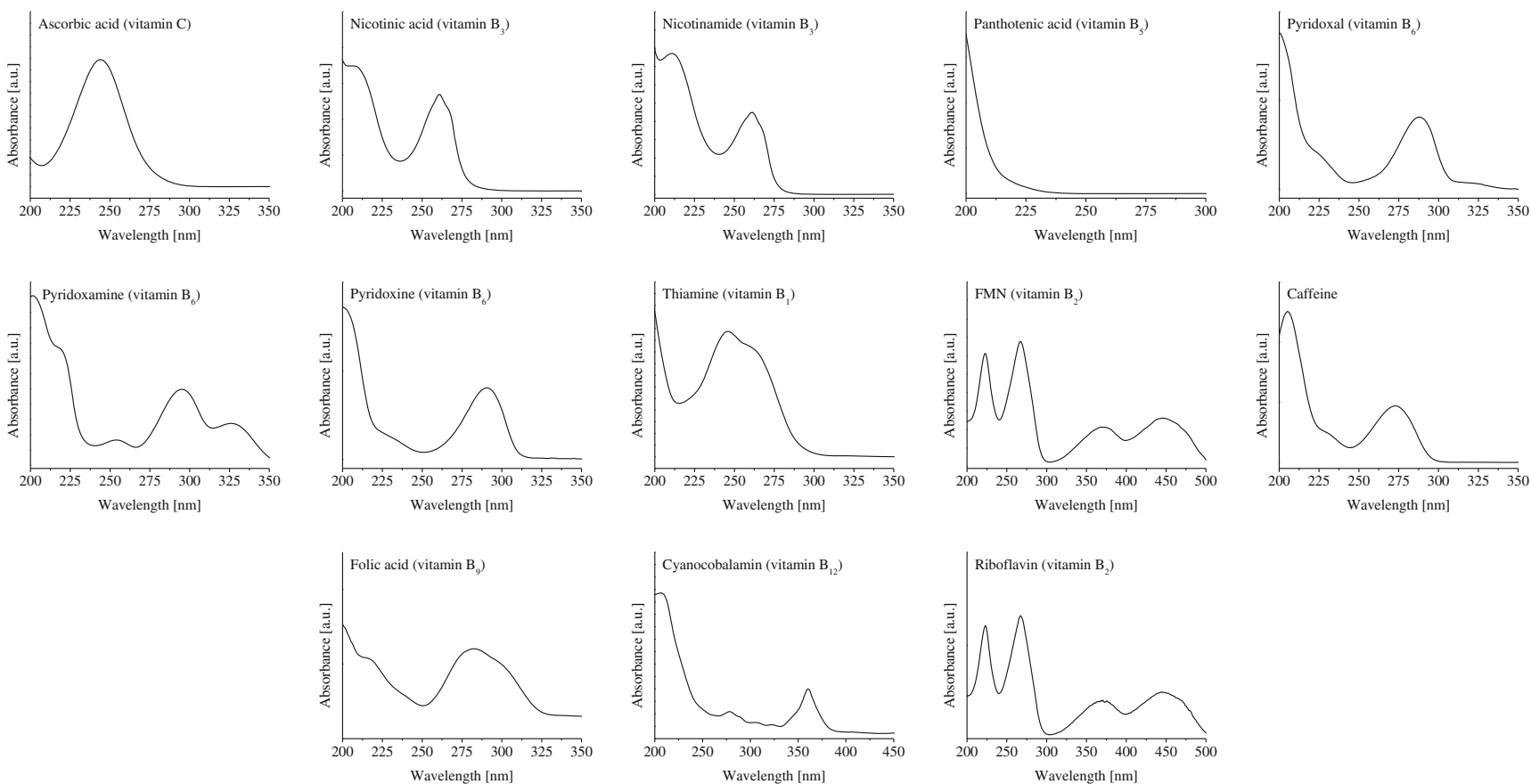

Fig. 3 Absorption spectra of water-soluble vitamins and caffeine

accuracy of the method was expressed as an average percentage of the vitamin/caffeine concentration in CRM.

The limit of detection (LOD) and limit of quantification (LOQ) were calculated on the basis of signal-to- noise ratio $(S / N)$ of three or ten, respectively. Instrument precision (intra- and interday) was checked from six consecutive injections of liquid and tablet energy drink samples.

Table 2 Linearity and sensitivity of HPLC-PDA and HPLC-FL methods for determination of caffeine and water-soluble vitamins

\begin{tabular}{|c|c|c|c|c|c|c|}
\hline Compound & Detection $[\mathrm{nm}]$ & Linearity range $\left[\mu \mathrm{g} \mathrm{mL}^{-1}\right]$ & Correlation coefficient $(r)$ & RSD of slope [\%] & $\mathrm{LOD}\left[\mathrm{ng} \mathrm{mL} L^{-1}\right]$ & $\mathrm{LOQ}\left[\mathrm{ng} \mathrm{mL}{ }^{-1}\right]$ \\
\hline Caffeine & 270 & $0-500$ & 0.999 & 0.7 & 23 & 77 \\
\hline Ascorbic acid & 245 & $0-500$ & 0.997 & 3.0 & 13 & 44 \\
\hline Nicotinic acid & 260 & $0-50$ & 0.999 & 0.3 & 20 & 66 \\
\hline Nicotinamide & 260 & $0-50$ & 0.999 & 1.4 & 63 & 211 \\
\hline Pantothenic acid & 202 & $0-50$ & 0.999 & 5.3 & 121 & 404 \\
\hline Thiamine & 245 & $0-50$ & 0.999 & 1.0 & 25 & 84 \\
\hline Folic acid & 280 & $0-10$ & 0.999 & 1.8 & 20 & 68 \\
\hline \multirow[t]{2}{*}{ Cyanocobalamin } & 207 & $0-10$ & 0.997 & 2.6 & 23 & 75 \\
\hline & 360 & $0-10$ & 0.999 & 2.3 & 63 & 210 \\
\hline \multirow[t]{2}{*}{ Pyridoxal } & 290 & $0-50$ & 0.999 & 0.7 & 62 & 206 \\
\hline & ex. 290/em. 390 & & 0.999 & 0.3 & 61 & 204 \\
\hline \multirow[t]{2}{*}{ Pyridoxamine } & 290 & $0-50$ & 0.999 & 2.0 & 52 & 173 \\
\hline & ex. 290/em. 390 & & 0.999 & 1.7 & 26 & 85 \\
\hline \multirow[t]{2}{*}{ Pyridoxine } & 290 & $0-50$ & 0.999 & 2.5 & 19 & 64 \\
\hline & ex. 290/em. 390 & & 0.999 & 2.0 & 19 & 64 \\
\hline \multirow[t]{2}{*}{ FMN } & 450 & $0-50$ & 0.999 & 1.4 & 113 & 375 \\
\hline & ex. $450 /$ em. 530 & & 0.999 & 1.4 & 16 & 52 \\
\hline \multirow[t]{2}{*}{ Riboflavin } & 450 & $0-50$ & 0.999 & 0.7 & 59 & 197 \\
\hline & ex. 450/em. 530 & & 0.999 & 0.7 & 8 & 28 \\
\hline
\end{tabular}


Table 3 The accuracy of the HPLC method expressed as an average percentage of the vitamin/ caffeine concentration in CRM

${ }^{\text {a }}$ Accuracy for pyridoxine was determined using PDA and FL detectors (in parenthesis)

${ }^{\mathrm{b}}$ The concentration of nicotinamide and pyridoxine

${ }^{\mathrm{c}}$ The concentration of caffeine (in parenthesis)

\begin{tabular}{llll}
\hline Concentration $\left[\mu \mathrm{g} \mathrm{mL}^{-1}\right]$ & \multicolumn{3}{l}{ Accuracy $[\%]$} \\
\cline { 2 - 4 } & Caffeine & Nicotinamide & Pyridoxine $^{\mathrm{a}}$ \\
\hline $1^{\mathrm{b}}(50)^{\mathrm{c}}$ & $101.1 \pm 1.7$ & $100.2 \pm 1.9$ & $98.7 \pm 0.8(99.5 \pm 1.7)$ \\
$5(100)$ & $96.9 \pm 0.9$ & $96.0 \pm 2.1$ & $96.8 \pm 3.0(99.6 \pm 1.1)$ \\
$10(200)$ & $97.0 \pm 3.8$ & $96.2 \pm 2.5$ & $95.4 \pm 3.3(98.6 \pm 1.9)$ \\
$25(300)$ & $99.2 \pm 1.6$ & $99.8 \pm 2.6$ & $96.9 \pm 1.6(99.4 \pm 3.0)$ \\
$50(500)$ & $101.3 \pm 0.1$ & $98.9 \pm 2.8$ & $98.2 \pm 2.1(99.8 \pm 1.8)$ \\
Average & $99.1 \pm 2.1$ & $98.2 \pm 2.0$ & $97.2 \pm 1.3(99.4 \pm 0.5)$ \\
\hline
\end{tabular}

\section{Statistical Analysis}

All determinations were carried out at least in triplicate and the results are presented as means \pm standard deviation.

\section{Results and Discussion}

\section{Analytical Characteristics of the HPLC Method}

In the present study, the HPLC-PDA method for the simultaneous separation and determination of caffeine and 12 watersoluble vitamin compounds was proposed. Moreover, the HPLC-FL method for vitamins $\mathrm{B}_{2}$ (in the form of FMN and riboflavin) and $\mathrm{B}_{6}$ (as pyridoxal, pyridoxamine, and pyridoxine) was described.

Detection wavelengths and retention times for caffeine and water-soluble vitamins separated using the proposed method are shown in Table 1. Typical HPLC chromatograms for standards and energy drink are shown in Figs. 1 and 2, respectively. The UV or UV/VIS absorption spectra of all separated compounds are also included (Fig. 3). The elution order was as follows: vitamin $\mathrm{C}$ (ascorbic acid), $\mathrm{B}_{3}$ (nicotinic acid, nicotinamide), $\mathrm{B}_{5}$ (pantothenic acid), $\mathrm{B}_{6}$ (pyridoxal, pyridoxamine, pyridoxine), $\mathrm{B}_{1}$ (thiamine), $\mathrm{B}_{2}(\mathrm{FMN})$, caffeine, vitamin $B_{9}$ (folic acid), $B_{12}$ (cyanocobalamin), and $B_{2}$ (riboflavin). Reproducibility of the retention times did not exceed $0.20 \mathrm{~min}$ (for thiamine). All tested compounds were separated using a gradient of mobile phase within $30 \mathrm{~min}$ including re-equilibration of the column before the next injection.

Nicotinamide and pyridoxine hydrochloride are the forms of vitamin $\mathrm{B}_{3}$ and vitamin $\mathrm{B}_{6}$, respectively, used in the production of energy drinks and vitamin supplements. Riboflavin and riboflavin 5'-phosphate (flavin mononucleotide, FMN) are the forms of vitamin $\mathrm{B}_{2}$ which are also used as a dye in selected beverages. These two forms of vitamin $\mathrm{B}_{2}$ can be well separated and quantified using both the HPLC-PDA and HPLC-FL. The HPLC-PDA method also allows the quantification of both forms of vitamin $\mathrm{B}_{3}$ (nicotinic acid and nicotinamide). Moreover, all vitamin $\mathrm{B}_{6}$ forms - pyridoxal, pyridoxamine, and pyridoxine - can be determined. It is not

Table 4 Intra- and interday instrument precision for determination of caffeine and water-soluble vitamins in energy drinks

\begin{tabular}{|c|c|c|c|c|c|c|c|c|c|}
\hline \multirow{3}{*}{\multicolumn{2}{|c|}{ Compound }} & \multicolumn{4}{|l|}{ Energy drink } & \multicolumn{4}{|c|}{ Tablet energy drink } \\
\hline & & \multicolumn{2}{|l|}{ Intraday } & \multicolumn{2}{|l|}{ Interday } & \multicolumn{2}{|l|}{ Intraday } & \multicolumn{2}{|l|}{ Interday } \\
\hline & & $\begin{array}{l}\text { Mean } \pm \mathrm{SD} \\
{\left[\mathrm{mg} 100 \mathrm{~mL}^{-1}\right]}\end{array}$ & RDS [\%] & $\begin{array}{l}\text { Mean } \pm \text { SD } \\
{\left[\mathrm{mg} 100 \mathrm{~mL}^{-1}\right]}\end{array}$ & $\operatorname{RDS}[\%]$ & $\begin{array}{l}\text { Mean } \pm \mathrm{SD} \\
{[\mathrm{mg} / \text { tablet }]}\end{array}$ & $\operatorname{RDS}[\%]$ & $\begin{array}{l}\text { Mean } \pm \mathrm{SD} \\
{[\mathrm{mg} / \mathrm{tablet}]}\end{array}$ & $\operatorname{RDS}[\%]$ \\
\hline \multicolumn{2}{|l|}{ Caffeine } & $32.65 \pm 0.04$ & 0.12 & $32.64 \pm 0.06$ & 0.19 & $59.85 \pm 0.09$ & 0.15 & $59.72 \pm 0.04$ & 0.07 \\
\hline \multicolumn{2}{|c|}{ Nicotinamide } & $6.29 \pm 0.03$ & 0.42 & $6.42 \pm 0.02$ & 0.27 & $8.01 \pm 0.03$ & 0.33 & $8.03 \pm 0.04$ & 0.45 \\
\hline \multicolumn{2}{|c|}{ Pantothenic acid } & $1.96 \pm 0.03$ & 1.59 & $1.96 \pm 0.03$ & 1.40 & $3.01 \pm 0.02$ & 0.65 & $2.98 \pm 0.01$ & 0.49 \\
\hline \multicolumn{2}{|l|}{ Thiamine } & - & - & - & - & $0.55 \pm 0.00$ & 0.64 & $0.56 \pm 0.01$ & 1.83 \\
\hline \multicolumn{2}{|l|}{ Folic acid } & - & - & - & - & $0.058 \pm 0.001$ & 1.44 & $0.063 \pm 0.001$ & 1.43 \\
\hline \multicolumn{2}{|c|}{ Cyanocobalamin } & n.d. & n.d. & n.d. & n.d. & - & - & - & - \\
\hline \multirow[t]{2}{*}{ Pyridoxine } & PDA & $0.67 \pm 0.01$ & 1.87 & $0.68 \pm 0.01$ & 1.73 & $0.71 \pm 0.00$ & 0.56 & $0.72 \pm 0.00$ & 0.45 \\
\hline & FL & $0.71 \pm 0.01$ & 0.90 & $0.71 \pm 0.01$ & 0.80 & $0.73 \pm 0.00$ & 0.35 & $0.77 \pm 0.01$ & 0.84 \\
\hline \multirow[t]{2}{*}{ Riboflavin } & PDA & $0.35 \pm 0.00$ & 0.63 & $0.35 \pm 0.00$ & 0.52 & $1.52 \pm 0.02$ & 1.23 & $1.45 \pm 0.01$ & 0.53 \\
\hline & FL & $0.36 \pm 0.00$ & 0.27 & $0.36 \pm 0.00$ & 0.50 & $1.61 \pm 0.02$ & 1.19 & $1.54 \pm 0.00$ & 0.30 \\
\hline
\end{tabular}

n.d. not detected (<LOD) 


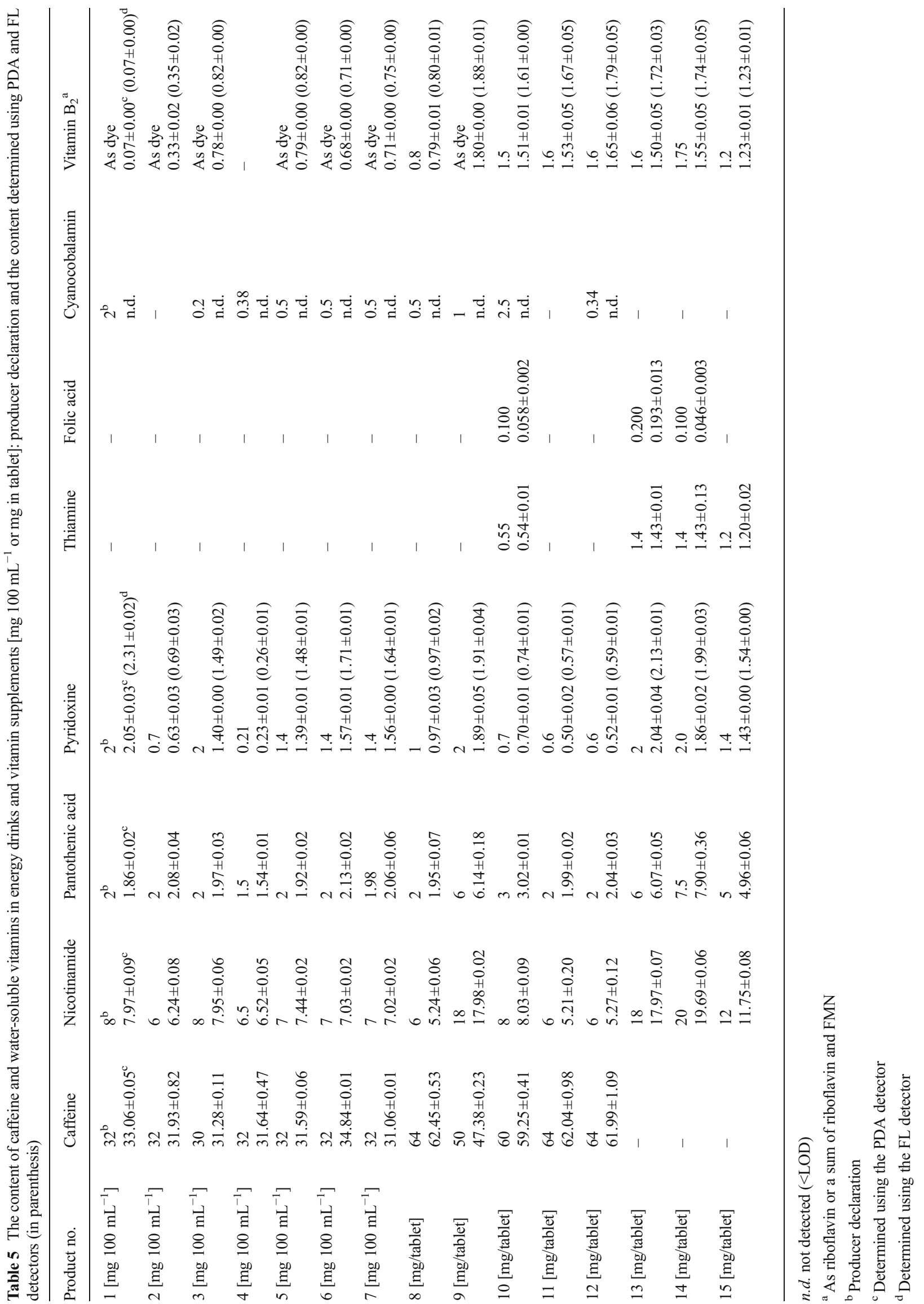


excluded that the proposed methods could be useful for watersoluble vitamin determination in a matrix containing all forms of vitamins $\mathrm{B}_{2}, \mathrm{~B}_{3}$, and $\mathrm{B}_{6}$ after appropriate sample preparation and purification. The developed HPLC-PDA and HPLCFL methods were validated for linearity and sensitivity (Table 2), accuracy (Table 3) as well as for intra- and interday instrument precision (Table 4).

Quantification of the tested compounds was performed using the external standard method. The relative standard deviation (RSD) values of the standard curve slopes were below $5.3 \%$ (for pantothenic acid at the wavelength of $202 \mathrm{~nm}$ ). Linear correlation coefficients $(r)$ for standard curves for all compounds were not lower than 0.997 (Table 2). The order of sensitivity of the HPLC-PDA, expressed as a LOD, was as follows: ascorbic acid $<$ pyridoxine $<$ nicotinic acid $=$ folic acid $<$ caffeine $=$ cyanocobalamin $($ at $207 \mathrm{~nm})<$ thiamine $<$ pyridoxamine $<$ riboflavin $<$ pyridoxal $<$ nicotinamide $=$ cyanocobalamin (at $360 \mathrm{~nm}$ ) $<$ FMN $<$ pantothenic acid. The LOD determined using the FL detector was as follows: riboflavin $<$ FMN $<$ pyrydoxine $<$ pyridoxamine $<$ pyridoxal (Table 2).

Accuracy of the HPLC-PDA and HPLC-FL methods (Table 3) was confirmed using CRMs of nicotinamide (vita$\min \mathrm{B}_{3}$ ), pyridoxine (vitamin $\mathrm{B}_{6}$ ), and caffeine. It was found that the accuracy for caffeine and nicotinamide determination, expressed as an average percentage of the caffeine/vitamin concentration in CRM, was 99.1 and $98.2 \%$, respectively. The concentration of pyridoxine could be determined with the accuracy of $97.2 \%$ when the PDA detector was used. The accuracy of the HPLC-FL was higher (99.4\%).

Instrument precision (Table 4) was checked from six consecutive injections of the tested sample. The intraday (the daily) and interday (day-to-day) RSD values of the system were not higher than 1.87 and $1.73 \%$, respectively, for liquid energy drink. For tablet energy drink, intra- and interday instrument precision was 1.44 and $1.83 \%$, respectively.

\section{Quantification of Caffeine and Water-Soluble Vitamins in Energy Drinks and Vitamin Supplements}

The validated HPLC-PDA and HPLC-FL methods were applied to 12 different energy drinks: seven liquid drinks and five in the form of tablet. Moreover, three vitamin supplements were included in the study for extending the method for vitamins which cannot generally be found in energy drinks (vitamins $\mathrm{B}_{1}$ and $\mathrm{B}_{9}$ ). Table 5 presents the declared amount of caffeine and water-soluble vitamins and the values obtained using the proposed HPLC-PDA and HPLC-FL methods. Caffeine and vitamins declared by the producers were detected in all the tested products with the exception of vitamin $\mathrm{B}_{12}$. The declared level of maximal $5 \mathrm{ng}$ of vitamin $\mathrm{B}_{12}$ per $\mathrm{mL}$ is too low for its detection (LOD for vitamin $\mathrm{B}_{12}$ in applied conditions was 23 and $63 \mathrm{ng} \mathrm{mL}^{-1}$ at the wavelengths of
207 and $360 \mathrm{~nm}$, respectively). Ascorbic acid can be also separated from other water-soluble vitamins, but it cannot be properly quantified in some products because of the influence of interferences (quantitative results not shown). Ascorbic acid was not present in liquid energy drinks.

The results obtained by the proposed HPLC method and the declared values are generally comparable with the exception of caffeine in liquid energy drinks. The results obtained in this study are slightly higher than the amount declared by the producers. The purity of the caffeine peak was confirmed, which may indicate that some energy drink producers use "technological allowance" in order to prevent the possible decrease of this compound during prolonged shelf-life.

\section{Conclusions}

The aim of the present study was to develop a chromatographic method for the separation and quantification of caffeine and water-soluble vitamins. The new HPLC-PDA and HPLC-FL methods were validated and applied to 15 products: energy drinks and vitamin supplements. The proposed HPLC method allows separation of 13 compounds: ascorbic acid, nicotinic acid, nicotinamide, pantothenic acid, pyridoxal, pyridoxamine, pyridoxine, thiamine, riboflavin 5 '-phosphate (flavin mononucleotide), caffeine, folic acid, cyanocobalamin, and riboflavin in a relatively short time (30 min including reequilibration time). The HPLC-FL method is selective for the determination of vitamins $\mathrm{B}_{2}$ (as FMN and riboflavin) and $\mathrm{B}_{6}$ (as pyridoxal, pyridoxamine, and pyridoxine). The proposed HPLC-PDA method is suitable for quantification of caffeine and water-soluble vitamins (nicotinamide, pantothenic acid, pyridoxine, thiamine, FMN, folic acid, and riboflavin) in energy drinks and vitamin supplements. The declared level of vitamin $B_{12}$ in these products is too low for its quantification, whereas ascorbic acid, if present in tablet energy drinks, may co-elute with interfering compounds overestimating its quantity.

The proposed separation method is simple and sensitive; thus, it can be carried out in any laboratory equipped with HPLC-PDA or HPLC-FL systems for routine investigations whether energy drinks meet the quantity requirements. They can also be an alternative for existing methods of watersoluble vitamin determinations in pharmaceutical preparations. It cannot be also excluded that these methods may be useful for water-soluble vitamin determinations in other matrices containing all forms of $\mathrm{B}_{2}, \mathrm{~B}_{3}$, and $\mathrm{B}_{6}$ vitamins after appropriate sample preparation.

Conflict of Interest Anna Gliszczyńska-Świgło declares that she has no conflict of interest. Iga Rybicka declares that she has no conflict of 
interest. This article does not contain any studies with human or animal subjects.

Open Access This article is distributed under the terms of the Creative Commons Attribution License which permits any use, distribution, and reproduction in any medium, provided the original author(s) and the source are credited.

\section{References}

Abourashed EA, Mossa JS (2004) HPTLC determination of caffeine in stimulant herbal products and power drinks. J Pharm Biomed Anal 36:617-620

Aranda M, Morlock G (2006) Simultaneous determination of riboflavin, pyridoxine, nicotinamide, caffeine and taurine in energy drinks by planar chromatography-multiple detection with confirmation by electrospray ionization mass spectrometry. J Chromatogr A 1131: 253-260

Ball GFM (2006) Vitamins in foods. Analysis, bioavailability, and stability. Taylor and Francis, Boca Raton

Euromonitor International (2013) Global sports and energy drinks: where consumer lifestyles and "lifestyle branding" meet

Euromonitor International (2014) Vitamins and dietary supplements. Accessed 7 March 2014

Gámiz-Gracia L, Luque de Castro MD (1997) An HPLC method for the determination of vitamin $\mathrm{B}_{1}$, caffeine, acetylsalicylic acid, and the impurities of salicylic acid in a pharmaceutical preparation. J Liq Chromatogr Relat Technol 20:2123-2133

Hadad GM, Abdel Salam RA, Soliman RM, Mesbah MK (2012) Rapid and simultaneous determination of antioxidant markers and caffeine in commercial teas and dietary supplements by HPLC-DAD. Talanta 101:38-44

Higdon JV, Frei B (2006) Coffee and health: a review of recent human research. Crit Rev Food Sci Nutr 46:101-123

Jafari MT, Rezaei B, Javaheri M (2011) A new method based on electrospray ionisation ion mobility spectrometry (ESI-IMS) for simultaneous determination of caffeine and theophylline. Food Chem 126:1964-1970

Jiang W, Wu Y, Jiang X (2013) Coffee and caffeine intake and breast cancer risk: an updated dose-response meta-analysis of 37 published studies. Gynecol Oncol 129:620-629

Leacock RE, Stankus JJ, Davis JM (2011) Simultaneous determination of caffeine and vitamin $\mathrm{B}_{6}$ in energy drinks by high-performance liquid chromatography (HPLC). J Chem Educ 88:232-234

Miura K, Hughes MC, Green AC, van der Pols JC (2014) Caffeine intake and risk of basal cell and squamous cell carcinomas of the skin in an 11-year prospective study. Eur J Nutr 53:511-520

Okamoto H, Nakajima T, Ito Y (2002) Simultaneous determination of ingredients in a vitamin-enriched drink by micellar electrokinetic chromatography. J Pharm Biomed Anal 30:815-822
Patil PN (2012) Caffeine in various samples and their analysis with HPLC - a review. Int J Pharm Sci Rev Res 16(2):76-83

Peri-Okonny UL, Wang SX, Stubbs RJ, Guzman NA (2005) Determination of caffeine and its metabolites in urine by capillary electrophoresis-mass spectrometry. Electrophoresis 26:2652-2663

Perrone D, Donangelo CM, Farah A (2008) Fast simultaneous analysis of caffeine, trigonelline, nicotinic acid and sucrose in coffee by liquid chromatography-mass spectrometry. Food Chem 110:1030-1035

Poerner RN, Bragagnolo N (2013) Identification and quantification of bioactive compounds in coffee brews by HPLC-DAD-MS. J Food Compos Anal 32:105-115

Powers HJ (2003) Riboflavin (vitamin $\mathrm{B}_{2}$ ) and health. Am J Clin Nutr 77: $1352-1360$

Prediger RD (2010) Effects of caffeine in Parkinson's disease: from neuroprotection to the management of motor and non-motor symptoms. J Alzheimers Dis 20:S205-S220. doi:10.3233/JAD-2010091459

Samanidou V, Tsagiannidis A, Sarakatsianos I (2012) Simultaneous determination of polyphenols and major purine alkaloids in Greek Sideritis species, herbal extracts, green tea, black tea, and coffee by high-performance liquid chromatography-diode array detection. J Sep Sci 35:608-615

Sather K, Vernig T (2011) Determination of caffeine and vitamin $B_{6}$ in energy drinks by high-performance liquid chromatography (HPLC). Concordia Coll J Anal Chem 2:84-91

Sriram K, Manzanares W, Joseph K (2012) Thiamine in nutrition therapy. Nutr Clin Pract 27:41-50

Sultan MA, Maher HM, Alzoman ZN, Alshehree MM, Rizk MS, Elshahed MS, Olah IV (2013) Capillary electrophoretic determination of antimigraine formulations containing caffeine, ergotamine, paracetamol and dompridone or metoclopramide. J Chromatogr Sci 51:502-510. doi:10.1093/chromsci/bms 175

Tokusoglu MÖ, Kemal Ü (2002) Optimized method for simultaneous determination of catechin, gallic acid, and methylxanthine compounds in chocolate using RP-HPLC. Eur Food Res Technol 215: 340-346

Uccella S, Mariani A, Wang AH, Vierkant RA, Cliby WA, Robien K, Anderson KE, Cerhan JR (2013) Intake of coffee, caffeine and other methylxanthines and risk of type I vs type II endometrial cancer. Br J Cancer 109:1908-1913

Zen JM, Ting YS (1997) Simultaneous determination of caffeine and acetaminophen in drug formulations by square-wave voltammetry using a chemical modified electrode. Anal Chim Acta 342:175-180

Zhao Y, Lunte CE (1997) Determination of caffeine and its metabolites by micellar electrokinetic capillary electrophoresis. J Chromatogr B Biomed Sci Appl 688:265-274

Zucconi S, Volpato C, Adinolfi F, Gandini E, Gentile E, Loi A, Fioriti L (2013) Gathering consumption data on specific consumer groups of energy drinks. Supporting Publications 2013:EN-394. [190 pp.]. www.efsa.europa.eu/publications 